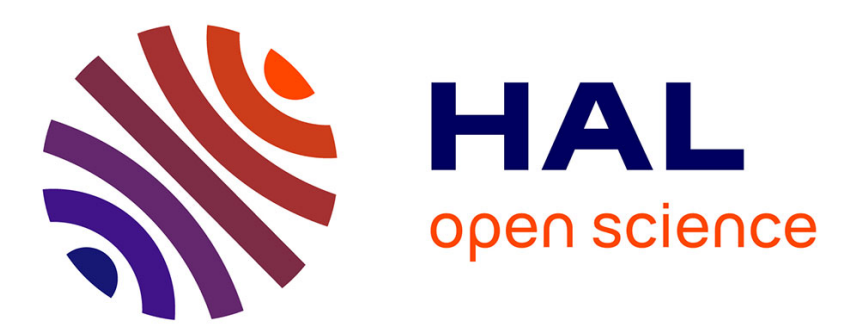

\title{
Design, Simulation and Experimental Results of Taipan 300, a New Autonomous Underwater Vehicle Prototype
}

\author{
Vincent Creuze, Olivier Parodi, Xianbo Xiang
}

\section{To cite this version:}

Vincent Creuze, Olivier Parodi, Xianbo Xiang. Design, Simulation and Experimental Results of Taipan 300, a New Autonomous Underwater Vehicle Prototype. OCEANS, May 2009, Bremen, Germany. 10.1109/OCEANSE.2009.5278200 . lirmm-00379315

\section{HAL Id: lirmm-00379315 \\ https://hal-lirmm.ccsd.cnrs.fr/lirmm-00379315}

Submitted on 21 May 2009

HAL is a multi-disciplinary open access archive for the deposit and dissemination of scientific research documents, whether they are published or not. The documents may come from teaching and research institutions in France or abroad, or from public or private research centers.
L'archive ouverte pluridisciplinaire HAL, est destinée au dépôt et à la diffusion de documents scientifiques de niveau recherche, publiés ou non, émanant des établissements d'enseignement et de recherche français ou étrangers, des laboratoires publics ou privés. 


\title{
Design, simulation and experimental results of Taipan 300,
}

\section{a new Autonomous Underwater Vehicle prototype}

\author{
Vincent Creuze, Olivier Parodi, and Xianbo Xiang
}

\begin{abstract}
In this paper we present a new small Autonomous Underwater Vehicle (AUV) called Taipan 300. First, we detail its technical features. Then, we explain how the particular hardware design of this vehicle makes its recovery easier in case of software or hardware failure. In fact this prototype offers enhanced safety measures in order to detect computer failure and to facilitate vehicle localization after it has resurfaced. In a third part, we describe the sliding control used. The last part consists in the presentation of the results obtained during experiments.
\end{abstract}

\section{INTRODUCTION}

$\mathrm{F}$ OR some years, the use and the sophistication level of Autonomous Underwater Vehicles (A.U.V.) have substantially increased. We can distinguish a "depth limit" for the different types of existing AUV. Indeed, from about 300 meters, the structure, the dimensions and the characteristics of these vehicles change. On the one hand, the AUVs specified for deep water, as for example Hugin 3000, Sea Oracle and Alistar 3000, have a maximum depth of 3000 meters, a high autonomy, substantial dimensions and a weight that requires a heavy logistic.

On the other hand, due to industrial and scientific requirements, the necessity of navigating in very shallow water has emerged. Some AUVs (Gavia [1], Remus [2], Maya [3], MMT3000 [4], Oberon [5], Starbug [6]...) with less autonomy, reduced dimensions, more modular parts and a reduced logistic, are the perfect tools for the investigation of shallow water environment.

Our prototype Taipan 300 has been developed in the purpose of being manually launched from the shore, navigating in very shallow waters and positioning with dead reckoning data and GPS fix. At the surface, the AUV should be able to transmit trials data to our missions' computer via a radio link. Applications are CTD measurements (Conductivity Temperature Depth), survey, bathymetry measurements, videos or biology in shallow water. Moreover the AUV must be able to navigate within less than 2 meters deep waters (lagoon, lake) with a near zero pitching angle.

Finally, Taipan 300 can be very easily reconfigured and

V. Creuze is with the LIRMM Laboratoire d'Informatique de Robotique et de Microélectronique de Montpellier UMR5506 CNRS / University Montpellier 2, 161 rue Ada, 34392 Montpellier Cedex 5, FRANCE (phone: +33-467-418-514; fax: +33-467-418-500; e-mail: creuze@ lirmm.fr).

O. Parodi is also with the LIRMM CNRS/University Montpellier 2 (e-mail: parodi@lirmm.fr). fitted with a video camera or an acoustic modem.

Recently, we have used Taipan 300 to perform CTD measurements. Obtained data have been shared with hydrologists in order to model undersea freshwater sources and to estimate their flow.

Currently, we use Taipan 300 in order to test a new method of seabed detection with single beam acoustic emitters (echo sounders). This seabed perception method is based on a combination of diffraction properties of sound and backscattering properties of the bottom. Two types of seabed equation can be generated depending on the aperture geometry of the acoustic transducer: a circular transducer leads to a robust 2D-equation [7] whereas a rectangular transducer can be used to determine 3D equations [8]. Offline static results have already been presented in 2005 for the 2D case [7]. We now try to implement and test this method online with the AUV. A special acoustic front part has been designed to embed the acoustic transducer.

In this paper, we describe the whole technical features of this new AUV prototype. Due to its lightness and mechanical resistance (the main part of the body is carbonmade), it can easily been manipulated and launched even from the shore.

In a second part, we detail how the hardware design takes into account the safety of the vehicle and how the recovery is made easier. A special external hardware watchdog timer has been developed. In case of failure, this latter can directly manage some hardware peripherals (motor, radio, GPS).

Then, we remind of sliding control principles used by Taipan 300 to follow its mission trajectories. We also shortly present the hardware in loop simulator associated with the vehicle.

The last part consists in the presentation of results obtained during experiments in the Salagou Lake (France).

At last, section VII concludes this work and presents our current research with this vehicle. 


\section{TEChNiCAL FEATURES OF THE VEHICLE}

Taipan 300 (Fig. 1) is a non commercial research AUV prototype. It has been developed by LIRMM (Laboratory of Computer Science, Robotics, and Microelectronics of Montpellier, France). This laboratory depends on CNRS (French National Research Organization) and Montpellier 2 University.

The vehicle is based on the mechanical structure of CALAS, an autonomous training target created by CNIM (La Seyne, France). All the electronics inside the vehicle have been redesigned to convert this target into a programmable scientific autonomous vehicle. The front part of the original vehicle has also been mechanically fully redesigned. We have added bow fins in order to allow self submersion from surface without ballast tank.

We also have fitted the vehicle with GPS and UHF antennas, for positioning and mid-range communications $(2 \mathrm{~km})$ purpose. For quick data transfer, a waterproof Ethernet plug has been specially designed. In order to perform freshwater tracking, the vehicle has also a CTD sensor (Conductivity, Depth, and Temperature).

The white nose of the vehicle has also been reshaped so has to contain two echo-sounders (obstacles avoidance and bottom following), a small Inertial Measurement Unit (IMU) and a WIFI transceiver (for short range communications and debugging).

The central part of hull (yellow part on fig. 1) is made of carbon fiber, combining thinness, lightness, and high pressure resistance (30 bars). Other parts of the vehicle are made of anodized aluminum (propeller, rudders, CTD bracket) or ostaform $^{\mathrm{TM}}$ (the white acoustic nose). As it is very light, it can be launched from the shore by a single person. Dimensions, weight and range of Taipan 300 are given in Table I.

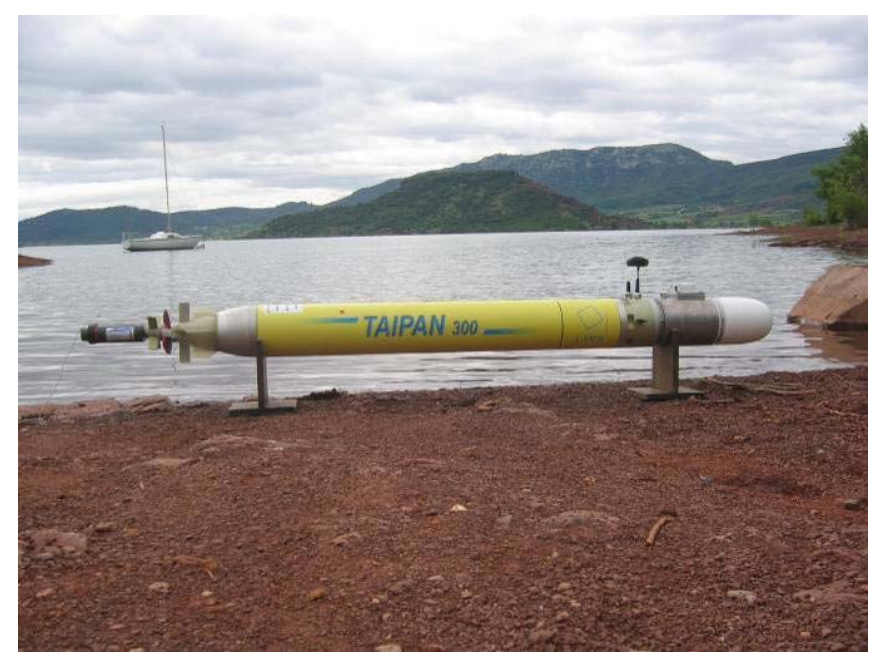

Fig. 1. Taipan 300 Autonomous Underwater Vehicle on the shore of Salagou Lake.

Moreover, depending of the mission goals, the CTD sensor can very easily be replaced by an acoustic modem or a video camera.

In order to communicate with the AUV and to program missions, we use a rugged laptop linked to a GPS receiver and a UHF transceiver (battery powered). Thus we can either control the vehicle from the shore or from a small boat.

TABLE I

\begin{tabular}{lc} 
& TAIPAN 300 TECHNICAL FEATURES \\
\hline Weight & $30 \mathrm{~kg}$ \\
Length & $2.1 \mathrm{~m}$ \\
Diameter & $0.15 \mathrm{~m}$ \\
Maximum depth & $300 \mathrm{~m}$ \\
Battery autonomy & 1 hour \\
Materials & Carbon, aluminum, plastic \\
Range & $5.8 \mathrm{~km}$ \\
CPU & PC104 Celeron 400MHz \\
Data storage & 4Go Compact Flash \\
Positioning & - GPS receiver \\
Sensor & - IMU MTi Xsens \\
& - Depth echo-sounders \\
Communication & - CTD sensor \\
& - Long range UHF \\
Emergency recovering & Transceiver \\
& - Wifi \\
\hline
\end{tabular}

\section{SAFETY AND RECOVERY}

During the design of Taipan 300, we made a particular effort to ensure that the vehicle could be easily recovered even in case of software or hardware failure.

Of course, as many other vehicles, Taipan 300 embeds an external autonomous acoustic pinger, which automatically turns on when in the water (autonomy: 3 days). Moreover, the most important aspect of the safety is that we have developed new hardware architecture. In this architecture, the UHF transceiver is not only used to communicate, but also to transmit the AUV position in case of failure. The novelty of our method lies in the ability of this system to transmit position even if the computer is totally out of order.

To achieve this, we have designed an especially dedicated external watchdog timer, which controls a multiplexer (MUX). In case of failure, this MUX connects the UHF transceiver serial input directly to the GPS serial output, thus transmitting by radio the GPS NMEA frames (4800bps) two kilometers around the AUV. The GPS and radio are also immediately switched to a separate power supply. Then an UHF transceiver embedded on the surface vessel gives the AUV position. Of course, the hardware watchdog timer also stops the motor of the vehicle (floatability brings it to the surface). 
The external Watchdog is mainly made of a FPGA (FieldProgrammable Gate Array) circuit connected (inputs) to two of the digital outputs of the CPU. This circuit is supplied by a separate power supply (NiMH). The FPGA is also connected to the MUX, the reset input of the CPU, the power relay of the motor and a power relay that switches radio and gps to a separate power supply (in case of failure).

When there is no computer failure, after the operating system has started, the main program of Taipan 300 is launched. This program checks periodically (every 100ms) the state of the vehicle (abnormal movement, actuators or sensors failure, leak detection, vehicle temperature, excessive depth). Once these checks have succeeded, the program sends back a signal to the internal watchdog of the computer and to the external hardware watchdog timer. This signal is two bits wide. Both bits must be different and they must toggle at each iteration. This toggle guarantees that the main program of the AUV is properly running.

If the program fails or the CPU stops (which is traduced by the absence of stimulation or toggle), after a short configurable delay, the external watchdog enters in security mode, switching the power of the motor off, and routing the GPS data directly to the radio.

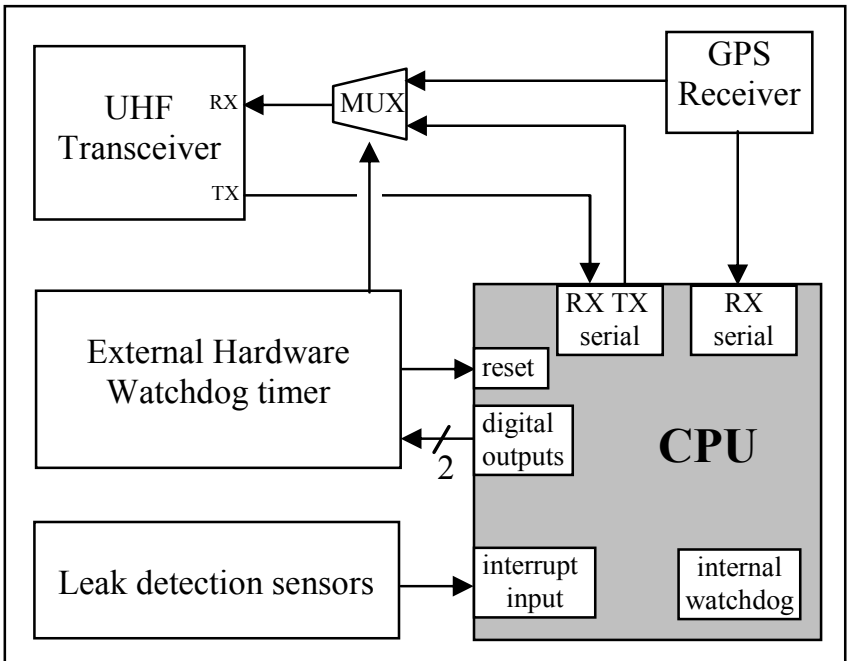

Fig. 2. Safety management of Taipan 300 (MUX stands for multiplexer). If the external watchdog timer is not periodically stimulated by the computer, it redirects GPS data directly to the UHF Radio (allowing surface recovery), and it resets the computer.

\section{CONTROL}

Underwater Vehicles are nonlinear systems. Their dynamics are usually represented by equation (1) [9].

$$
M_{\eta}(\eta) \ddot{\eta}+C_{\eta}(v, \eta) \dot{\eta}+D_{\eta}(v, \eta) \dot{\eta}+g_{\eta}(\eta)=\tau_{\eta}
$$

where $\eta=[x, y, z, \phi, \theta, \psi]^{T}$ denotes the position and orientation vector with coordinates in the earth-fixed frame, $v=[u, v, w, p, q, r]^{T}$ denotes the linear and angular velocity vector with coordinates in the body fixed frame, and $\tau_{\eta}$ denotes the input forces and torques.
To command our vehicle, we use a sliding-mode control [10]. In this paper, we will only describe the method used to control movements in a vertical plane (depth and pitching angle). The control in the horizontal plane (heading) can be easily found by a similar way.

We assume that linear and angular velocities are low and that non-hydrodynamic phenomena do not occur. First, the model of the AUV (1) is linearized and expressed as:

$$
\dot{\mathbf{x}}=\mathbf{A} \mathbf{x}+\mathbf{B u}
$$

Then we define a sliding surface [10] called $\sigma(\mathrm{x})$ :

$$
\sigma(\mathbf{x})=\mathbf{s}^{\mathbf{t}} \mathbf{x}=0
$$

Stability on this sliding surface is achieved if the sliding condition is satisfied [9][10]. Introducing $\eta>0$ (this scalar $\eta$ is different from the $\eta$ vector used in (1)), the sliding condition can be written as :

$$
\dot{\sigma}(\mathbf{x})=-\eta \operatorname{sgn}(\sigma(\mathbf{x}))
$$

In fact we have:

$$
\sigma(\mathbf{x}) \dot{\sigma}(\mathbf{x})=-\eta \sigma(\mathbf{x}) \operatorname{sgn}(\sigma(\mathbf{x}))=-\eta|\sigma(\mathbf{x})|
$$

Derivation of $\sigma(\mathrm{x})$ in (3), gives us $\dot{\mathbf{x}}$ that can be replaced by $\mathrm{Ax}+\mathrm{Bu}(2)$. Replacing $\dot{\sigma}(\mathbf{x})$ in (4), gives:

$$
\mathrm{s}^{\mathrm{t}}(\mathbf{A x}+\mathbf{B u})=-\eta \operatorname{sgn}(\sigma(\mathbf{x}))
$$

Then we can determine $\mathbf{u}$, the command to be applied.

$$
\mathbf{u}=-\left(\mathbf{s}^{\mathbf{t}} \mathbf{B}\right)^{-1} \mathbf{s}^{\mathbf{t}} \mathbf{A} \mathbf{x}-\left(\mathbf{s}^{\mathbf{t}} \mathbf{B}\right)^{-1} \eta \operatorname{sgn}(\sigma(\mathbf{x}))
$$

This equation can also be written as follows:

$$
\mathbf{u}=-\mathbf{K} \mathbf{x}+\mathbf{K}_{\mathrm{s}} \eta \operatorname{sgn}(\sigma(\mathbf{x}))
$$

with:

$$
\begin{aligned}
& \mathbf{K}=\left(\mathbf{s}^{\mathbf{t}} \mathbf{B}\right)^{-1} \mathbf{s}^{\mathbf{t}} \mathbf{A} \\
& \mathbf{K}_{\mathbf{s}}=-\left(\mathbf{s}^{\mathbf{t}} \mathbf{B}\right)^{-1}
\end{aligned}
$$

Thus, this control law is composed of a nominal part, based on a feedback linearizing, and an additional term aimed at dealing with unmodeled dynamics.

To limit power consumption due to chattering of the actuators, we can replace $\operatorname{sgn}(\sigma(\mathbf{x}))$ in $(8)$ by $\tanh (\sigma(\mathbf{x}) / \Phi)$, where $\Phi$ can be adjusted to tune the chattering attenuation. 
Then we obtain (10).

$$
\mathrm{u}=-\mathrm{Kx}+\mathrm{K}_{\mathrm{s}} \eta \tanh (\sigma(\mathrm{x}))
$$

where $\mathbf{u}$ is the command vector to be applied to the actuators (bow and stern fins), $\mathbf{x}$ is the state vector of the vehicle, $\mathbf{K}$ is a gain matrix, $\eta$ is a strictly positive constant, and $\sigma(\mathbf{x})$ is the chosen sliding surface.

For example, in the case of our vehicle, under the assumptions given above, and due to some neglected or null hydrodynamic parameters, $\beta$ the angle to be applied to the stern rudders is given by (11).

$\beta=\mathrm{k}_{1} \mathrm{w}+\mathrm{k}_{2} \mathrm{q}+\mathrm{k}_{3} \theta+\eta \tanh \left[\left(\mathrm{s}_{1} \mathrm{w}+\mathrm{s}_{2} \mathrm{q}+\mathrm{s}_{3}\left(\theta-\theta_{d}\right)+\mathrm{s}_{4}\left(\mathrm{z}-\mathrm{z}_{\mathrm{d}}\right)\right) / \phi\right]$

where $\mathrm{w}, \mathrm{q}, \theta$, and $\mathrm{z}$ denote the linear velocity, the angular velocity, the pitching angle, and depth. Constants $\mathrm{z}_{\mathrm{d}}$ and $\theta_{\mathrm{d}}$ are the desired depth and pitching angle. Coefficients $\mathrm{s}_{1}, \mathrm{~s}_{2}$, $\mathrm{s}_{3}$, and $\mathrm{s}_{4}$ depend on the chosen sliding surface.

\section{SIMULATION}

Our research group has developed a new real time multivehicles hybrid simulator for heterogeneous vehicles (underwater and/or surface vehicles). This simulator (Fig. 3), called Thetis [12], allows us to simulate the behavior of one or more communicating underwater vehicles. It performs hardware in loop (HIL) simulations including virtual sensors allowing sensing of the virtual environment. During simulation, the simulator and Taipan 300 are linked via Ethernet so that all computation related to the vehicle's control and environment mapping are achieved by Taipan's embedded computer.

Before experimentation, we have tested many situations/parameters with this simulator and the obtained experimental results presented in the following paragraph agree with those obtained with the simulator.

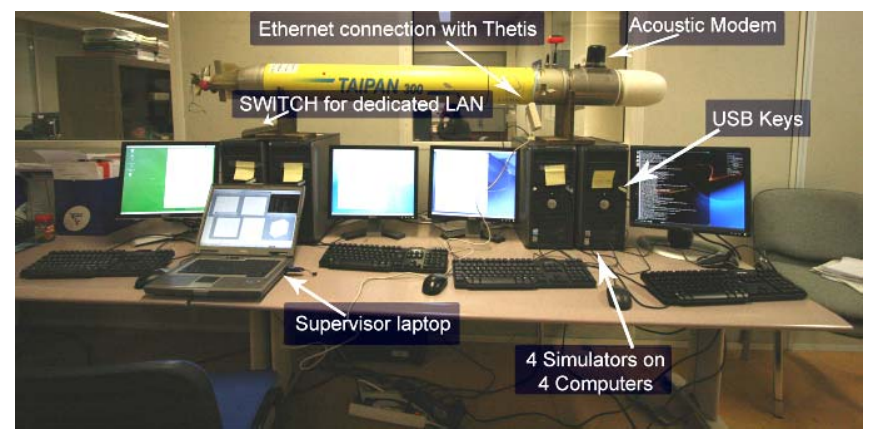

Fig. 3. Hardware in loop real time simulator - The main program runs on the vehicle's computer while other computers simulate environment, sensors responses, and actuators.

\section{EXPERIMENTS}

\section{A. Experimental conditions}

The following sequence of experiments has been conducted in the Salagou Lake (Herault, France). The maximal depth of this artificial fresh water area $\left(7.5 \mathrm{~km}^{2}\right)$ is 20 meters. Experiments took place during summer, and we have tested the vehicle both under calm and windy conditions (wind: 20 knots, waves: $50 \mathrm{~cm}$ ).

\section{B. Mission interface}

All the experimental missions have been programmed with a dedicated Matlab ${ }^{\mathrm{TM}}$ interface linked to a GPS receiver and to an UHF transceiver. Once the mission is entered, the interface determines the timeout delay to be applied and then sends the mission waypoints to the AUV (using the radio device). This latter sends the mission back to the laptop so as the interface checks the transmission validity. As soon as the AUV has received by radio the confirmation of the mission validity, it starts. As the vehicle is launched from the shore, it first navigates at the surface (GPS guidance) in order to reach the starting point of its mission. Then, it dives.

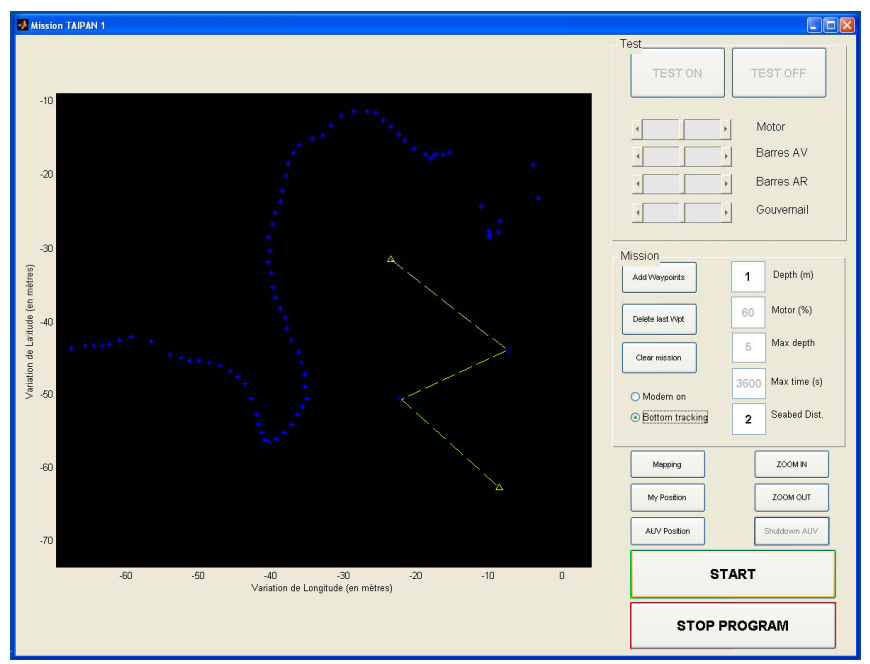

Fig.4. A three waypoints mission definition (yellow) with the programming interface of Taipan 300. Blue dots represent the northern shore of the lake.

\section{Experimental Results}

On the following figures, we can see the beginning of a mission. The AUV was programmed to head at $155^{\circ}$. It had to navigate 0.4 meters deep so as to be easily tracked from the surface. Its pitching angle was set to be $-2^{\circ}$ (static default value of the vehicle).

Figure 5 shows the depth control of the vehicle. Until $\mathrm{t}=16 \mathrm{~s}$ Taipan 300 is navigating at the surface and is accelerating in order to get enough speed to dive (there is no ballast tank). 
From $\mathrm{t}=16 \mathrm{~s}$ to $\mathrm{t}=25 \mathrm{~s}$, the vehicle is diving. During this phase, its pitching angle reaches $-10^{\circ}$ and then returns to its default value $-2^{\circ}$ (Fig. 6).

After $\mathrm{t}=25 \mathrm{~s}$, Taipan 300 has reached its desired heading and depth. The control maintains these desired values. There is however a small oscillation around the desired depth value $( \pm 10 \mathrm{~cm}$ around $0.4 \mathrm{~m})$ and the pitching angle value $\left( \pm 3^{\circ}\right.$ around $-2^{\circ}$ ). This is due to the small waves in the Lake, which directly affect the measured pressure (the vehicle is very near from the surface) and thus the AUV controller (work is currently done to filter such disturbances close to the surface).

After $\mathrm{t}=45 \mathrm{~s}$, until the rest of the mission, results are not shown here because they are similar to those obtained between $\mathrm{t}=25 \mathrm{~s}$ and $\mathrm{t}=45 \mathrm{~s}$.

Moreover, it is interesting to notice that during the acceleration and immersion phases $(16 \mathrm{~s}<\mathrm{t}<25 \mathrm{~s})$, the heading control error can reach $-7^{\circ}$ (Fig. 7). This is due to the speed of the motor, which is set to its maximal value (AUV speed $=2 \mathrm{~m} / \mathrm{s}$ ) during these phases. The resulting torque makes the vehicle roll and then rudder and fins are no more decoupled, inducing difficulties to achieve a correct heading control. Once the vehicle has fully submerged the motor speed is set to its cruising speed $(1.6 \mathrm{~m} / \mathrm{s})$ and then the rolling angle of the AUV becomes null, allowing a correct heading control.

Many other missions have been conducted in Salagou
Lake and at open sea, showing a good ability to reproduce the obtained results.

Although the overshoot in depth (Fig. 5) seems to be large when the vehicle dives, it has to be noticed that its value $(45 \mathrm{~cm})$ remains constant regardless the desired immersion value $(0.4$ to $300 \mathrm{~m})$. This result is very good in comparison with other vehicles performances and is satisfying regarding the safety of Taipan 300 .

During the optimization of the sliding-mode control parameters (particularly as regards the overshoot), some missions have aborted due to excessive depth regarding the assigned depth $(\max$ depth $=1.2 *$ mission defined depth or absolute max depth). In this case the hardware watchdog interrupt did not occurred because the fault was detected by the software and the vehicle was able to surface and warn the shore station by radio.

It occurred one time that the CPU has crashed probably due to a power failure. Then, the hardware watchdog has stopped the motor and as the vehicle came back to the surface, the shore station received its position by radio. Thus it was shortly recovered.

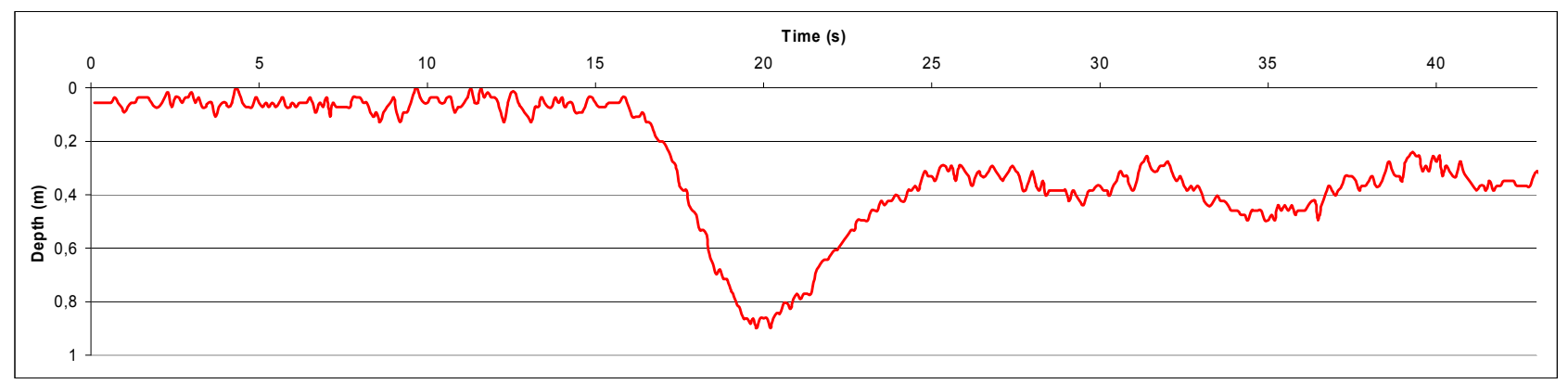

Fig. 5. Depth control along the trajectory.

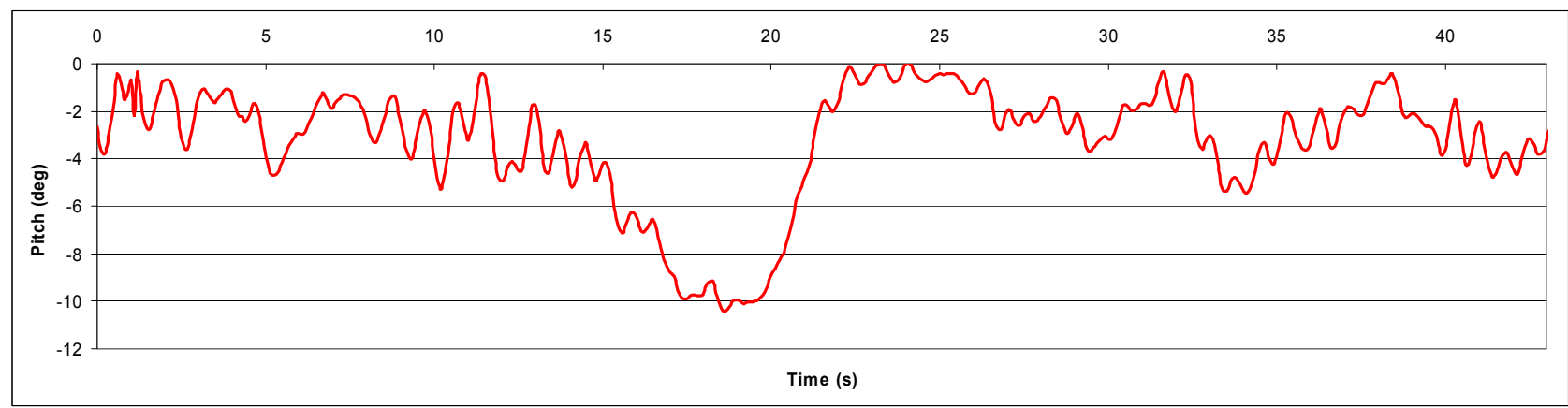

Fig. 6. Pitching angle along the trajectory. 


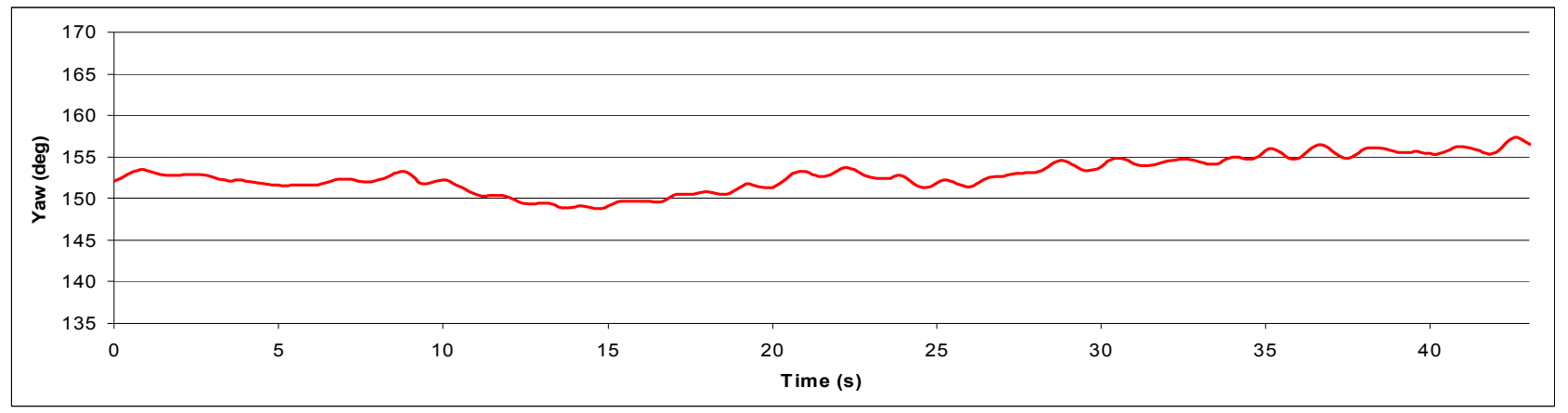

Fig. 7. Heading control along the trajectory.

\section{CONCLUSION}

In this paper we have presented a new non commercial AUV prototype, specially designed to be easily recovered and to be launched from the shore. The presented results show a good ability to follow straight trajectories at constant depth and constant pitching angle. As it is fitted with a CTD sensor (Conductivity Depth Temperature), we presently use TAIPAN 300 to study undersea freshwater sources. Obtained CTD measurements are used by hydrologists to model the source and then to determine the freshwater flow of the source.

Moreover, a second vehicle is being constructed and both will be fitted with acoustic modems in order to perform multi-AUV cooperation.

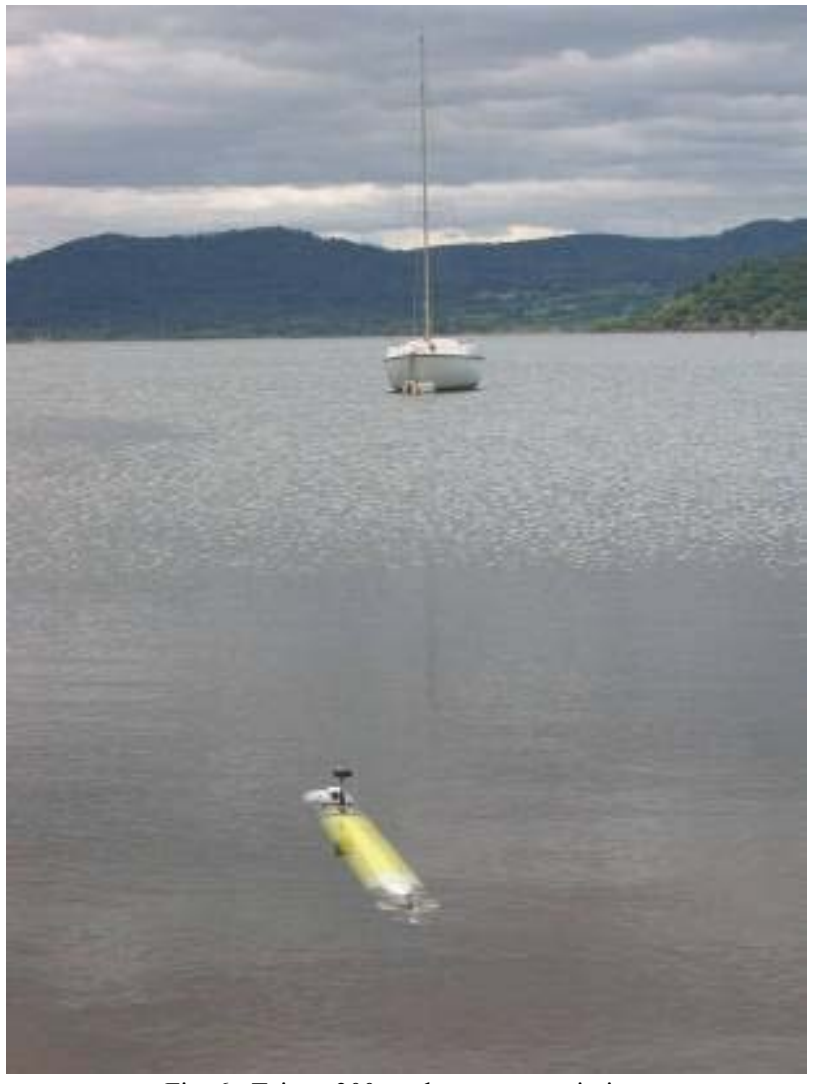

Fig. 6. Taipan 300 ready to start a mission.

\section{ACKNOWLEDGMENT}

The authors would like to thank Malo Frieh (CNIM, La Seyne-sur-mer, France) and Olivier Company (LIRMM, France) for their advice and help during the mechanical design of new parts of the vehicle.

\section{REFERENCES}

[1] H. Johannsson, H. Thorhallsson, and T. Hafsteinsson, "An efficient method of combining detection and identification of seafloor objects using Gavia AUV," IEEE OCEANS 2006, Boston, USA, Sept. 2006.

[2] R.P. Stokey, C. von Alt, B. Allen, et al, "Development of the REMUS 600 Autonomous Underwater Vehicle," IEEE Oceans 2005, Washington, USA, Sept. 2005.

[3] R. Madhan, E. Desa, S. Prabhudesai, Luís Sebastião, António Pascoal, E. Desa, A. Mascarenhas, P. Maurya, G. Navelkar, S. Afzulpurkar, S. Khalap, "Mechanical Design and Development Aspects of a Small AUV-MAYA," IFAC MCMC2006, Conference on Manoeuvring and Control of Marine Craft, Lisbon, Portugal, 2006.

[4] V. Gornak, A. Inzartsev, O. Lvov, Y. Matvienko, and A. Scherbatyuk, "MMT 3000 A small AUV of new series of IMTP FEB RAS," IEEE OCEANS 2006, Boston, MA, USA, Sept. 2006

[5] S. Williams, and I. Mahon, "Design of an unmanned underwater vehicle for reef surveying," IFAC Symposium on Mechatronic Systems, Manly NSW, Australia, 06 Sep. - 08 Sep. 2004

[6] M. Dunbabin, J. Roberts, K. Usher, G. Winstanley, and P. Corke, "A Hybrid AUV Design for Shallow Water Reef Navigation," IEEE ICRA 2005, International Conference on Robotics and Automation, Barcelona, Spain, 18-22 April 2005, pp.2105-2110.

[7] V. Creuze, B. Jouvencel, and P. Baccou, "Using Sound Diffraction to Determine the Seabed Slope," IEEE IROS 2005, International Conference on Intelligent Robots \& Systems, Edmonton, Canada, pp. 1731-1736, August 2005.

[8] V. Creuze, B. Jouvencel, and P. Baccou, "3D-Bottom Tracking based on Acoustic Diffraction for Autonomous Underwater Vehicles," IEEE ICAR 2005, International Conference on Advanced Robotics, Seattle, WA, USA, July 2005.

[9] T.I. Fossen, Marine Control Systems - Guidance, Navigation, and Control of Ships, Rigs and Underwater Vehicles, Marine Cybernetics, Trondheim, Norway, 2002, pp.49-113.

[10] J.J. Slotine, and W. Li, Applied Nonlinear Control, Prentice Hall, Englewood Cliffs, 1991, pp. 81-102.

[11] V. Creuze, Seabed based navigation for Autonomous Underwater Vehicles, Navigation reference terrain pour véhicules autonomes sous-marins, PhD Thesis, Montpellier 2 University, Montpellier, France, nov. 2002.

[12] O. Parodi, V. Creuze, and B. Jouvencel, "Communication within Thetis a real-time Multi-Vehicles Hybrid Simulator, ” ISOPE 2008, International Offshore an Polar Engineering Conference, Vancouver, Canada, July 2008. 